\title{
Global Domination upon Edge Addition Stable Graphs
}

\author{
K. Kavitha \\ Research Scholar \\ Department of Mathematics, Madras Christian \\ College, Chennai - 600059
}

\begin{abstract}
Let $\mathrm{G}$ be a simple, finite and connected graph. A dominating set $\mathrm{D}$ of a graph $\mathrm{G}$ is a global dominating set if $\mathrm{D}$ is also a dominating set of $\bar{G}$. The global domination number $\gamma_{g}(G)$ is the minimum cardinality of a minimal global dominating set of G. A graph is global domination edge critical if addition of any arbitrary edge changes the global domination number. On the other hand, a graph is global domination edge stable if addition of any arbitrary edge has no effect on the global domination number. In this paper, we study the concepts of global domination and connected global domination upon edge addition stable property for cycle and path graphs. We determine sharp bounds on the global domination and connected global domination number of global domination, total global domination and connected global domination edge addition stable graphs.
\end{abstract}

\section{Keywords}

domination, global domination, connected global domination, edge addition stable. AMS Subject Classification: 05C69

\section{PRELIMINARIES}

In our study, we consider only simple, finite and undirected graphs. In this section, we review the notions of domination, global domination and connected global domination $[2,3,4]$.

\section{Definition 1.1}

Let $\mathrm{G}=(\mathrm{V}, \mathrm{E})$ be a graph. A subset $\mathrm{D}$ of $\mathrm{V}$ is called a dominating set of $\mathrm{G}$ if every vertex in $\mathrm{V}-\mathrm{D}$ is adjacent to at least one vertex in D. A dominating set D is called a minimal dominating set if no proper subset of $\mathrm{D}$ is a dominating set. The domination number $\gamma(\mathrm{G})$ of a graph $\mathrm{G}$ is the minimum cardinality of a minimal dominating set in $\mathrm{G}$.

\section{Definition 1.2}

A dominating set $\mathrm{D}$ of a graph $\mathrm{G}$ is called a global dominating set if $\mathrm{D}$ is also a dominating set of $\bar{G}$. The minimum cardinality of a minimal global dominating set is denoted by $\gamma_{\mathrm{g}}$ and is called the global domination number of G.

\section{Definition 1.3}

A connected dominating set $D$ of a graph $G$ is called a connected global dominating set if $\mathrm{D}$ is also a connected dominating set of $\bar{G}$. The connected global domination number of $G$ is the minimum cardinality of a minimal connected global dominating set is denoted by $\gamma_{\mathrm{cg}}$.

\author{
N.G. David \\ Associate Professor \\ Department of Mathematics, Madras Christian \\ College, Chennai - 600059
}

\section{Definition 1.4}

Let $\mathrm{P}$ be a graph parameter. A graph $\mathrm{G}$ is said to be $P$ - edge addition critical if $\mathrm{P}(\mathrm{G}+\mathrm{e}) \neq \mathrm{P}(\mathrm{G})$ for every edge e of $\bar{G}$, the complement of $\mathrm{G}$. A graph $\mathrm{G}$ is said to be $P$ - edge addition stable if $\mathrm{P}(\mathrm{G}+\mathrm{e})=\mathrm{P}(\mathrm{G})$ for every edge e of $\bar{G}$.

\section{Global Domination upon Edge Addition Stable Graphs}

In this section, we investigate 'global domination edge addition stable' property for cycles and paths [1].

\section{Definition 2.1}

A graph $\mathrm{G}$ is said to be global domination edge addition stable or $\gamma_{\mathrm{g}}^{+}$-stable for short, if addition of any edge to G does not change the global domination number. In other words, a graph $\mathrm{G}$ is $\gamma_{\mathrm{g}}{ }^{+}$-stable if $\gamma_{\mathrm{g}}(\mathrm{G}+\mathrm{e})=\gamma_{\mathrm{g}}(\mathrm{G})$ for every edge e $\in$ $\mathrm{E}(\bar{G})$.

\section{Theorem 2.2}

For $\mathrm{n} \geq 5, \mathrm{n} \neq 3 \mathrm{k}+1, \mathrm{k} \geq 2$, cycle graphs $\mathrm{C}_{\mathrm{n}}$ are $\gamma_{\mathrm{g}}{ }^{+}$-stable.

\section{Proof}

Let $C_{n}: v_{1}, v_{2}, \ldots, v_{n}$ be a cycle of length $n \geq 5$. Here $n$ is either 5 or takes one of the two forms $3 k$ or $3 k+2, k \geq 2$ (as $n$ $\neq 3 \mathrm{k}+1$ ). A global dominating set of $\mathrm{C}_{\mathrm{n}}$ can be obtained by taking $\mathrm{D}=\left\{\mathrm{v}_{3 \mathrm{i}-1} / \mathrm{i}=1,2, \ldots, \mathrm{k}\right\} \quad$ if $\mathrm{n}=3 \mathrm{k}$, $\mathrm{D}=\left\{\mathrm{v}_{3 \mathrm{i}+2} / \mathrm{i}=0,1,2, \ldots, \mathrm{k}\right\}$ if $\mathrm{n}=3 \mathrm{k}+2$ or $\mathrm{D}=\left\{\mathrm{v}_{1}, \mathrm{v}_{2}, \mathrm{v}_{4}\right\}$ when $n=5$. The different cases that arise when an edge is added between two non-adjacent vertices $v_{i}$ and $v_{j}$ in $C_{n}$, are such that $2 \leq \mathrm{d}\left(\mathrm{v}_{\mathrm{i}}, \mathrm{v}_{\mathrm{j}}\right) \leq\lfloor n / 2\rfloor-1$, where $\mathrm{d}\left(\mathrm{v}_{\mathrm{i}}, \mathrm{v}_{\mathrm{j}}\right)$ denotes the distance between $v_{i}$ and $v_{j}$, and in all these cases the global domination is not affected. Hence $\mathrm{C}_{\mathrm{n}}$ is $\gamma_{\mathrm{g}}{ }^{+}$- stable when $\mathrm{n} \neq 3 \mathrm{k}+1, \mathrm{k} \geq 1$.

\section{Corollary 2.3}

For $\mathrm{n}=3 \mathrm{k}+1, \mathrm{k} \geq 2$, cycle graphs $\mathrm{C}_{\mathrm{n}}$ are not $\gamma_{\mathrm{g}}{ }^{+}$-stable.

\section{Proof}

By using the labeling of $\mathrm{C}_{\mathrm{n}}$ as in the above theorem, global dominating set of $\mathrm{C}_{\mathrm{n}}, \mathrm{n}=3 \mathrm{k}+1$ is given by $\mathrm{D}=\left\{\mathrm{v}_{3 \mathrm{i}+1} / \mathrm{i}=0,1,2, \ldots, \mathrm{k}\right\}$. Up on adding an edge between non-adjacent vertices at distance 2 , the global domination number is reduced by 1 . Hence $C_{n}$ is not $\gamma_{g}{ }^{+}$- stable, when $\mathrm{n}=3 \mathrm{k}+1, \mathrm{k} \geq 2$. 


\section{Proposition 2.4}

$$
\begin{aligned}
& \text { For } n=5 \text { or } 3 k+1, k \geq 2, \\
& \gamma_{g}\left(C_{n}\right) \geq \gamma_{g}\left(C_{n}+e\right) \geq \gamma_{g}\left(C_{n}\right)-1 .
\end{aligned}
$$

\section{Theorem 2.5}

For $\mathrm{n} \geq 8, \mathrm{n} \neq 3 \mathrm{k}+1, \mathrm{k} \geq 3$, path graphs $\mathrm{P}_{\mathrm{n}}$ are $\gamma_{\mathrm{g}}{ }^{+}$-stable.

\section{Proof}

Let $\mathrm{P}_{\mathrm{n}}: \mathrm{v}_{1}, \mathrm{v}_{2}, \ldots, \mathrm{v}_{\mathrm{n}}$ be the path graph of order $\mathrm{n} \geq 8$. Here $\mathrm{n}$ takes one of the two forms $3 \mathrm{k}+2, \mathrm{k} \geq 2$ or $3 \mathrm{k}, \mathrm{k}$ $\geq 3$ (as $n \neq 3 \mathrm{k}+1)$. A global dominating set of $\mathrm{P}_{\mathrm{n}}$ can be obtained by taking $\mathrm{D}=\left\{\mathrm{v}_{3 \mathrm{i}+2} / \mathrm{i}=0,1,2, \ldots \mathrm{k}\right\}$ when $\mathrm{n}=3 \mathrm{k}+2$ and $\mathrm{D}=\left\{\mathrm{v}_{3 \mathrm{i}+2} / \mathrm{i}=0,1,2, \ldots \mathrm{k}-1\right\}$ when $\mathrm{n}=3 \mathrm{k}$. By adding an edge between non-adjacent vertices $v_{i}$ and $v_{j}$, $1 \leq \mathrm{i}<\mathrm{j} \leq \mathrm{n}$ in $\mathrm{P}_{\mathrm{n}}$, the global domination number is not changed. Hence $\mathrm{P}_{\mathrm{n}}$ is $\gamma_{\mathrm{g}}{ }^{+}$-stable when $\mathrm{n} \neq 3 \mathrm{k}+1, \mathrm{k} \geq 3$.

\section{Corollary 2.6}

For $\mathrm{n}=3 \mathrm{k}+1, \mathrm{k} \geq 2$, path graphs $\mathrm{P}_{\mathrm{n}}$ are not $\gamma_{\mathrm{g}}^{+}$-stable.

\section{Proof}

Let $P_{n}: v_{1}, v_{2}, \ldots, v_{n}$ be the path graph of order $\mathrm{n}=3 \mathrm{k}+1, \mathrm{k} \geq 2$. Addition of an edge between the pendant and support vertex $\mathrm{v}_{1}$ and $\mathrm{v}_{\mathrm{n}-1}$, global domination number is decreased by one. Hence $\mathrm{P}_{\mathrm{n}}, \mathrm{n}=3 \mathrm{k}+1, \mathrm{k} \geq 2$ are not $\gamma_{\mathrm{g}}^{+}$- stable.

\section{Result 2.7}

For $\mathrm{n}=5$ and 6 , path graphs $\mathrm{P}_{\mathrm{n}}$ are not $\gamma_{\mathrm{g}}{ }^{+}$-stable.

\section{Example 2.8}

Consider the path graph $\mathrm{P}_{7}: \mathrm{v}_{1}, \mathrm{v}_{2}, \ldots, \mathrm{v}_{7}$.

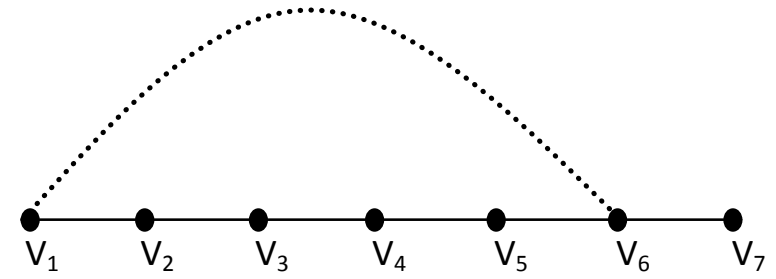

Figure 1

The minimal global dominating set is $\left\{\mathrm{v}_{2}, \mathrm{v}_{5}, \mathrm{v}_{7}\right\}$. The minimal global dominating set for $\mathrm{P}_{7}+\mathrm{e}\left(=\mathrm{v}_{1} \mathrm{v}_{6}\right)$ is $\left\{\mathrm{v}_{3}, \mathrm{v}_{6},\right\}$, thereby decreasing the global domination number by one.

\section{CONNECTED DOMINATION UPON EDGE ADDITION STABLE GRAPHS}

In this section, we investigate "connected global domination edge addition stable' property for cycles and paths.

\section{Definition 3.1}

A graph $\mathrm{G}$ is said to be a connected global domination edge addition stable or $\gamma_{\mathrm{cg}}{ }^{+}$-stable for short, if addition of any edge to $\mathrm{G}$ does not change the connected global domination number. In other words, a graph $\mathrm{G}$ is $\gamma_{\mathrm{cg}}{ }^{+}$-stable if $\gamma_{\mathrm{cg}}(\mathrm{G}+\mathrm{e})=\gamma_{\mathrm{cg}}(\mathrm{G})$ for every edge e $\in \mathrm{E}(\bar{G})$.

\section{Theorem 3.2}

For $\mathrm{n} \geq 7$, cycle graphs $\mathrm{C}_{\mathrm{n}}$ are $\gamma_{\mathrm{cg}}{ }^{+}$- critical.

Proof

Let $C_{n}: v_{1}, v_{2}, \ldots, v_{n}$ be the cycle graph of order $n$, $\mathrm{n} \geq 7$. Global connected dominating set with minimum cardinality can be obtained by taking $\mathrm{D}=\left\{\mathrm{v}_{1}, \mathrm{v}_{2}, \ldots, \mathrm{v}_{\mathrm{n}-2}\right\}$ and therefore, $\gamma_{c g}\left(C_{n}\right)=n-2$. By adding an edge between vertices at distance 2 , global connected domination number is reduced by 1 . But adding an edge e between vertices $v_{i}$ and $\mathrm{v}_{\mathrm{j}}, \mathrm{i}<\mathrm{j}$ at distance $\mathrm{k}, 3 \leq \mathrm{k} \leq\lfloor\mathrm{n} / 2\rfloor$, results in a smaller global connected dominating set with vertices $\left\{\mathrm{v}_{\mathrm{i}}, \mathrm{v}_{\mathrm{j}}, \mathrm{v}_{\mathrm{j}-1}, \mathrm{v}_{\mathrm{j}-2}, \ldots\right.$, $\left.\mathrm{v}_{\mathrm{i}+3}, \mathrm{v}_{\mathrm{j}+1}, \mathrm{v}_{\mathrm{j}+2}, \ldots, \mathrm{v}_{\mathrm{i}-3}\right\}$, where the addition in the subscripts are such that, when they exceed $n$, subtract $n$; reduces the global connected domination number by 2 . Therefore cycle graphs are $\gamma_{\mathrm{cg}}{ }^{+}$-critical.

\section{Result 3.3}

Cycle graphs $\mathrm{C}_{5}$ and $\mathrm{C}_{6}$ are $\gamma_{\mathrm{cg}}{ }^{+}$-stable.

Example 3.4

Consider the cycle graph $\mathrm{C}_{7}$ with $\mathrm{V}=\left\{\mathrm{v}_{1}, \mathrm{v}_{2}, \mathrm{v}_{3}, \mathrm{v}_{4}, \mathrm{v}_{5}, \mathrm{v}_{6}, \mathrm{v}_{7}\right\}$

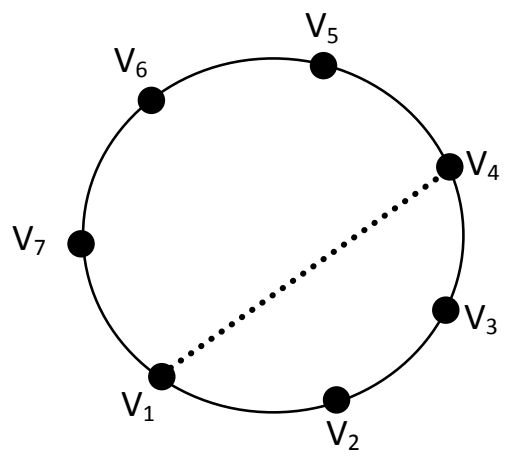

Figure 4

An global connected dominating set is $\left\{\mathrm{v}_{1}, \mathrm{v}_{2}, \mathrm{v}_{3}, \mathrm{v}_{4}, \mathrm{v}_{5}\right\}$, implying $\gamma_{c g}\left(C_{7}\right)=5$. After adding an edge e between vertices 
$\mathrm{v}_{1}$ and $\mathrm{v}_{4}$, global connected dominating set for $\left(\mathrm{C}_{7}+\mathrm{e}\right)$ is $\left\{\mathrm{v}_{1}, \mathrm{v}_{4}, \mathrm{v}_{5}\right\}$. Hence global connected domination number is reduced by 2 .

\section{Proposition 3.5}

(i) For $\mathrm{n} \geq 7, \gamma_{\mathrm{cg}}\left(\mathrm{C}_{\mathrm{n}}+\mathrm{e}\right)=\gamma_{\mathrm{cg}}\left(\mathrm{C}_{\mathrm{n}}\right)-1$ if an edge $\mathrm{e}$ is added between two vertices at distance two.

(ii) For $\mathrm{n} \geq 8, \gamma_{\mathrm{cg}}\left(\mathrm{C}_{\mathrm{n}}+\mathrm{e}\right)=\gamma_{\mathrm{cg}}\left(\mathrm{C}_{\mathrm{n}}\right)-2$ if an edge $\mathrm{e}$ is added between two vertices at distance more than two.

\section{Theorem 3.6}

For $\mathrm{n} \geq 7$, path graphs $\mathrm{P}_{\mathrm{n}}$ are not $\gamma_{\mathrm{cg}}{ }^{+}$-stable.

\section{Proof}

Let $P_{n}: v_{1}, v_{2}, \ldots, v_{n}$ be the path graph of order $n \geq 7$. The set of vertices $\left\{\mathrm{v}_{2}, \mathrm{v}_{3}, \ldots, \mathrm{v}_{\mathrm{n}-1}\right\}$ forms the minimal global connected dominating set. If an edge is added between $\mathrm{v}_{1}$ and $\mathrm{v}_{\mathrm{n}-1}$, a support vertex, the global connected domination number is decreased by one. On the other hand, if an edge is added between the pendant vertices the global connected domination number remains the same. Therefore, path graphs are not $\gamma_{\mathrm{cg}}{ }^{+}$- stable.

\section{Result 3.7}

For $\mathrm{n}=5$ and 6 , path graphs $\mathrm{P}_{\mathrm{n}}$ are $\gamma_{\mathrm{cg}}{ }^{+}$-stable.

\section{Proposition 3.8}

For $\mathrm{n} \geq 7, \gamma_{\mathrm{cg}}\left(\mathrm{P}_{\mathrm{n}}\right) \geq \gamma_{\mathrm{cg}}\left(\mathrm{P}_{\mathrm{n}}+\mathrm{e}\right) \geq \gamma_{\mathrm{cg}}\left(\mathrm{P}_{\mathrm{n}}\right)-2$.

\section{CONCLUSION}

In this present study, the concept of stability of global domination and connected global domination upon edge addition stable property for cycle and path graphs are investigated. In our future work, stability of different families of graphs for other kinds of domination upon edge addition is proposed.

5. REFERENCES $[1]$ D. Hanson, P. Wang, A note on extremal total domination edge critical graphs, Util. Math. 63(2003) $89-96$.

[2] F. Harary, Graph Theory, Narosa Publishing, Bombay, 1969.

[3] S.T. Hedetniemi and R.C. Laskar, Topics in Domination, Elsevier Science Publishers B.V., Netherlands, 1991.

[4] V.R. Kulli and B. Janakiram, The Total Global Domination Number of a Graph, Indian J. Pure appl. Math., 27(6) : 537 - 542, June 1996. 